Volume 13, No. 1, Juni 2014

ISSN 1411-514X (print)

ISSN 2355-7737 (online)

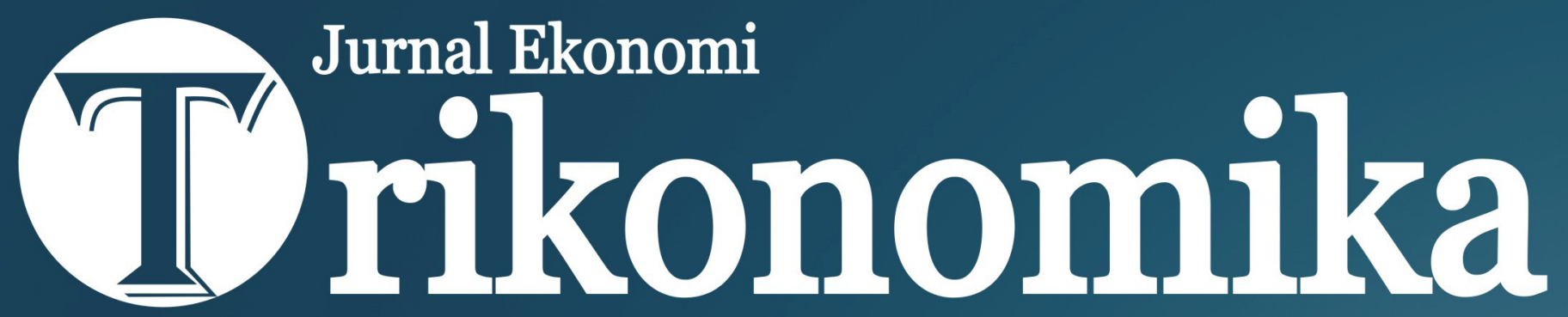


DAFTAR ISI

Trikonomika, Volume 13, No. 1, Juni 2014

Pengaruh Otonomi dan Akuntabilitas Perguruan Tinggi terhadap Kinerja Manajerial

Isnaeni Nurhayati

Keseimbangan Jangka Pendek dan Jangka Panjang Nilai Tukar Rupiah terhadap Dollar Amerika

Horas Djulius, Yudi Nurdiansyah

Kajian Kepemimpinan Transformasional, Komitmen Karyawan, Motivasi, Kepuasan Kerja, dan Kinerja Karyawan

Edy Saptono

$21-48$

Pengaruh Kualitas Pelayanan terhadap Kepuasan Mahasiswa Program Ekstensi Fakultas Ekonomi Universitas Jambi

Yenny Yuniarti

Determinan Profitabilitas Bank: Suatu Studi pada Bank yang Terdaftar di BEI

Jaja Suteja, Gerinata Ginting

Faktor Determinan Minat Wirausaha Mahasiswa Fakultas Ekonomi dan Bisnis Universitas

Negeri Gorontalo

Herwin Mopangga $78-90$

Pengaruh Upah dan Pengalaman Kerja terhadap Produktivitas Karyawan Kerajinan Ukiran Kabupaten Subang

Ardika Sulaeman

$91-100$

Analisis Harga Saham dan Rata-Rata Abnormal Return Sebelum dan Sesudah Ex-Dividend Date (Studi pada Emiten Indeks Kompas-100)

Alvin Mulya Hidayati $101-107$

Pengaruh Manajemen Laba Akrual dengan Pendekatan Revenue Discretionary Model terhadap Kinerja Perusahaan

Sepriahangga Wahyu Windharta, Nurmala Ahmar $108-118$ 


\title{
Pengaruh Manajemen Laba Akrual dengan Pendekatan Revenue Discretionary Model terhadap Kinerja Perusahaan
}

\author{
Sepriahangga Wahyu Windharta \\ STIE Perbanas Surabaya \\ J1. Nginden Semolo 34-36 Surabaya \\ E-Mail:2010310417@students.perbanas.ac.id \\ Nurmala Ahmar \\ STIE Perbanas Surabaya \\ J1. Nginden Semolo 34-36 Surabaya \\ E-Mail: Nurmala@perbanas.ac.id
}

\begin{abstract}
Accrual earnings management is a form of manipulation of financial statements on the accrual components to increase its profit in order to look good in the investors perception. This research approach discretionary revenue published by Stubben in 2010 with two different formulas are conditional revenue models and revenue models to measure the accrual earnings management to be proxies to the performance of the company. The purpose of this study was to analyze the effect of accrual earnings management by discretionary revenue approach on firm performance in manufacturing companies listed on the Stock Exchange. The Results of analysis for this study were 1) Accrual earnings management is measured using a Revenue Model does not affect the Return On Asset. 2) Accrual earnings management is measured using a Revenue Model does not affect the Tobin's q. 3) Accrual earnings management is measured using a Conditional Revenue Models effect on the Return On Asset. 4) Accrual earnings management is measured using a Conditional Revenue Models has no effect on Tobin's $q$.
\end{abstract}

Keywords: revenue discretionary, earning's management, return on asset, tobin's $q$.

\begin{abstract}
ABSTRAK
Manajemen laba akrual adalah suatu bentuk manipulasi laporan keuangan pada komponen akrual untuk meningkatkan laba perusahaan dalam rangka untuk terlihat baik dalam persepsi investor. Penelitian pendekatan pendapatan diskresioner yang dipublikasikan oleh Stubben pada tahun 2010 dengan dua formula yang berbeda adalah model pendapatan bersyarat dan model pendapatan untuk mengukur manajemen laba akrual menjadi proxy untuk kinerja perusahaan. Tujuan dari penelitian ini adalah untuk menganalisis pengaruh manajemen laba akrual dengan pendekatan pendapatan diskresioner pada kinerja perusahaan pada perusahaan manufaktur yang terdaftar di Bursa Efek. Hasil analisis untuk penelitian ini adalah 1) Manajemen laba akrual diukur dengan menggunakan Model Pendapatan tidak mempengaruhi Return On Asset. 2) Manajemen laba akrual diukur dengan menggunakan Model Pendapatan tidak mempengaruhi q Tobin. 3) Manajemen laba akrual diukur dengan menggunakan formula Pendapatan Model efek pada Return On Asset. 4) Manajemen laba akrual diukur dengan menggunakan Model Pendapatan Bersyarat tidak berpengaruh pada Tobin's Q.
\end{abstract}

Kata Kunci: revenue discretionary, manajemen laba, return on asset, tobin's q. 


\section{PENDAHULUAN}

Tujuan berdirinya suatu perusahaan adalah untuk dapat menjaga kelangsungan hidup perusahaan, melakukan pertumbuhan serta dapat meningkatkan laba maupun dapat mempertahankan angka laba agar terlihat konstan oleh pengguna laporan keuangan dari waktu ke waktu. Di mana ketiganya adalah pedoman menuju arah strategis semua organisasi bisnis. Salah satu strategi yang dilakukan oleh perusahaan agar dapat bersaing dalam bisnis global ini adalah dengan menggunakan praktik manajemen laba. Manajemen laba adalah pilihan kebijakan akuntansi yang dilakukan oleh manajer untuk tujuan spesifik yaitu para manajer memberikan perintah langsung kepada akuntan di perusahaan untuk memanipulasi angkaangka yang ada pada laporan keuangan perusahaan. Penelitian Dechow \& Skinner (2000) menunjukkan beberapa manajemen laba yang bisa dilakukan oleh manajer, seperti penjualan lebih cepat dan perubahan jadwal pengiriman produk.

Manajemen laba dapat diklasifikasikan menjadi tiga kategori yaitu akuntansi yang curang, manajemen akrual, dan manajemen laba nyata (Gunny, 2005). Manajemen laba dilakukan oleh para manajer perusahaan tidak lain untuk menutupi segala kekurangan yang dimiliki perusahaan agar terlihat baik oleh pengguna laporan keuangannya. Hal itu dapat dibuktikan dengan adanya skandal-skandal manajemen laba di Indonesia yang pernah dilakukan oleh perusahaan-perusahaan besar seperti PT Kimia Farma Tbk dan Lippo Bank Tbk. Pada tahun 2001 PT Kimia Farma Tbk melaporkan laba sebesar 132 milyar namun setelah diaudit ulang pada tahun 2002 laba sebenarnya perusahaan tersebut adalah 99,56 milyar yaitu 32,6 milyar lebih rendah dari laba sebelumnya (Parsaoran, 2009). Dalam laporan keuangan Lippo bank Tbk per 30 September 2002 yang disampaikan ke publik pada 28 November 2002 disebutkan total aktiva perseroan Rp 24 triliun dan laba bersih Rp 98 miliar. Namun dalam laporan ke BEJ pada 27 Desember 2002 total aktiva perusahaan berubah menjadi Rp 22,8 triliun rupiah (turun Rp 1,2 triliun) dan perusahaan merugi bersih $\mathrm{Rp}$ 1,3 triliun (Sumantyo, 2003).

Saat terjadi manajemen laba, informasi yang tersaji dalam laporan keuangan perusahaan dimungkinkan memiliki asimetri informasi. Asimetri informasi merupakan saat dimana manajer dalam perusahaan tersebut lebih mengetahui tentang kondisi perusahaan dimasa lampau maupun di masa yang akan datang dibandingkan investornya Ujiyantho \& Pramuka (2007). Ketika timbul asimetri informasi, keputusan ungkapan yang dibuat oleh manajer dapat mempengaruhi harga saham. Karena jika terjadi asimetri informasi antara investor yang lebih memiliki banyak informasi dengan investor yang kurang terinformasi akan menimbulkan biaya transaksi dan mengurangi likuiditas yang diharapkan dalam pasar untuk saham-saham perusahaan. Berbagai penjelasan diatas menjelaskan tentang bagaimana pihak eksternal yang paling sering dirugikan. Adanya ketimpangan tersebut menjadi alasan mengapa penelitian ini penting dilakukan agar pihak investor memiliki tambahan informasi agar lebih bijaksana dalam melakukan investasi.

Perubahan pada PSAK 1 tahun 2009 yang mulai efektif pada Januari tahun 2011 menjadikan bahan pertimbangan dalam penentuan tahun penelitian. Perubahan yang terjadi adalah pada laporan laba rugi, dimana sebelumnya hanya mewajibkan untuk menyajikan laporan laba rugi, dan setelah perubahan harus menyajikan laporan laba rugi komprehensif. Laporan laba rugi komprehensif merupakan laporan laba rugi yang ditambahkan dengan komponen pendapatan komprehensif lain. Adanya perubahan PSAK 1 tahun 2009 yang mulai efektif pada januari 2011 mempengaruhi penggunaan salah satu formula Revenue Discretionary. Formula tersebut adalah Conditioanal Revenue Model yang tidak dapat digunakan untuk tahun sampel diatas 2011. Akan tetapi hal tersebut tidak berpengaruh terhadap formula Revenue Model.

Pada penelitan ini manajemen laba di pengaruhkan pada kinerja perusahaan. Kinerja perusahaan dapat diukur dengan berbagai rasio keuangan, namun yang digunakan dalam penelitian ini adalah ROA dan Tobin's $Q$. Berdasarkan teori agensi, terdapat pemisahan fungsi antara pemilik organisasi dan pelaku organisasi (Jensen \& Meckling, 1976). Dari pemisahan fungsi tersebut dapat menimbulkan perbedaan tujuan atau kepentingan antara pemilik dan pelaku organisasi yang sering disebut konflik agency. Agar pengelola organisasi ini bertindak sesuai keinginan pemilik organisasi (prinsipal), maka principal perlu untuk mengeluarkan 
biaya untuk mengawasi kegiatan yang dilakukan pengelola (agen). Jika agen dan principal berupaya memaksimalkan utilitasnya masing-masing, serta memiliki keinginan dan motivasi yang berbeda, maka ada alasan untuk percaya bahwa agen (manajemen) tidak selalu bertindak sesuai keinginan principal. Konflik keagenan dapat mengakibatkan adanya sifat manajemen melaporkan laba secara oportunis untuk memaksimumkan kepentingan pribadinya. Jika hal ini terjadi akan mengakibatkan rendahnya kualitas laba. Salah satu ukuran kinerja perusahaan digunakan oleh manajer untuk mengambil keputusan.

Selain itu penelitian ini juga dapat dikaitkan dengan teori signaling. Teori tersebut merupakan teori bagaimana seharusnya perusahaan memberikan sinyal-sinyal berupa informasi tentang perusahaan terhadap pengguna laporan keuangan agar tidak terjadi asimetri informasi. Sinyal yang diberikan dapat dilakukan melalui pengungkapan informasi akuntansi seperti laporan keuangan Ujiyantho \& Pramuka (2007). Sinyal dapat berupa promosi atau informasi lain yang menyatakan bahwa perusahaan tersebut lebih baik dari pada perusahaan lain. Teori sinyal menjelaskan bahwa pemberian sinyal dilakukan oleh manajer untuk mengurangi asimetri informasi.

Ujiyantho \& Pramuka (2007) menyatakan bahwa dari sudut pandang teori akuntansi, manajemen laba sangat ditentukan oleh motivasi manajer perusahaan. Motivasi yang berbeda akan menghasilkan besaran manajemen laba yang berbeda, seperti antara manajer yang juga sekaligus sebagai pemegang saham dan manajer yang tidak sebagai pemegang saham. Dua hal tersebut akan mempengaruhi manajemen laba, sebab kepemilikan seorang manajer akan ikut menentukan kebijakan dan pengambilan keputusan terhadap metode akuntansi yang diterapkan pada perusahaan yang mereka kelola.

Dalam pendekatan Revenue Discretionary Model, Stubben (2010) mengembangkan model pendapatan dan akrual pada tingkat kuartalan karena model pendapatan kuartalan lebih kuat dan lebih baik. Pendapatan perkuartalan digunakan untuk mempermudah dalam mengontrol apabila terjadi manipulasi karena pendapatan dianggap sebagai ukuran yang obyektifdari kegiatan operasi perusahaan. Stubben mengembangkan dua formula yang berbeda yaitu Revenue Model dan Conditional Revenue Model. Kedua formula tersebut akan dibandingkan keandalannya dalam memprediksi adanya praktek manajemen laba pada sampel yang diteliti

\section{METODE}

Ditinjau dari tujuannya, penelitian ini termasuk jenis penelitian dasar, yaitu tipe penelitian yang berkaitan juga dengan pemecahan persoalan, tetapi dalam pengertian yang berbeda, yaitu berupa persoalan yang bersifat teoritis dan tidak mempunyai pengaruh secara langsung dengan penentuan kebijakan, tindakan atau kinerja tertentu.

Ditinjau dari sumber data yang diambil, penelitian ini dikatakan sebagai peneliti secara tidak langsung melalui media perantara. Data sekunder umumnya berupa bukti, catatan atau laporan historis yang telah tersusun (dokumenter) sehingga peneliti dapat langsung memprosesnya.

Populasi dalam penelitian ini adalah seluruh perusahaan manufaktur yang terdaftar di Bursa Efek Indonesia pada tahun 2007 hingga tahun 2012 sebanyak 179 perusahaan dengan menggunakan 716 data keuangan. Setelah dilakukan teknik pengambilan sampel dengan metode purposive sampling, didapat bahwa pada masing-masing model memiliki sampel yang berbeda. Pada Revenue Model terdapat 231 sampel sedangkan pada Conditional Revenue Model tedapat 374 sampel.

Revenue Model menekankan pada pendapatan perkuartalan yang diproksikan dengan piutang pertahun dengan asumsi bahwa apabila pendapatan perkuartal mampu menjelaskan piutang dengan baik, maka tidak akan terindikasi manajemen laba.

Revenue Model, Stubben (2010:701):

$\Delta \mathrm{AR}_{i t}=\alpha+\beta_{1} \Delta \mathrm{R} 1_{-} 3_{i t}+\beta_{2} \Delta \mathrm{R} 4_{i t}+\varepsilon_{i t}$

di mana:

AR = Piutang pada kuartal ke empat

R1_3 = Pendapatan dalam tiga kuartal pertama

R4 = Pendapatan dikuartal keempat.

$\varepsilon=$ error

Conditional Revenue Model lebih menekankan pada banyak aspek yang mempengaruhi pendapatan diskresioner. Aspek tersebut meliputi ukuran perusahaan (Size), umur perusahaan (Age), laba kotor (Gross Revenue Margin).

Conditional Revenue Model, Stubben (2010:701):

$$
\begin{aligned}
\Delta \mathrm{AR}_{i t}= & \alpha+\beta_{1} \Delta \mathrm{R}_{i t}+\beta_{2} \Delta \mathrm{R}_{i t} \times \mathrm{SIZE}+\beta_{3} \Delta \mathrm{R}_{i t} \mathrm{xAGE}_{i t} \\
& +\beta_{4} \Delta \mathrm{R}_{i t} \mathrm{x} \mathrm{AGE} \mathrm{SQ}_{i t}+\beta_{5} \Delta \mathrm{R}_{i t} \mathrm{x} \text { GRR_P } \mathrm{P}_{i t}+\beta_{6} \\
& \Delta \mathrm{R}_{i t} \mathrm{x}_{\mathrm{GRR}} \mathrm{N}_{i t}+\beta_{7} \Delta \mathrm{R}_{i t} \mathrm{xGRM}_{i t}+\beta_{8} \Delta \mathrm{R}_{i t} \mathrm{x} \\
& \mathrm{GRM}_{-} \mathrm{SQ}_{i t}+\varepsilon_{i t}
\end{aligned}
$$


di mana:

AR = Piutang akhir tahun

R1_3 = Pendapatan pada kuartal ke-3

$\mathrm{R}^{-}=$Pendapatan pada kuartal ke-4

$S I Z E=$ Natural $\log$ dari total aset akhir tahun

$A G E=$ Umur perusahaan (tahun)

$G R M=$ Margin kotor yang disesuaikan pada akhir tahun fiskal

$\mathrm{SQ}=$ Kuadrat dari variabel

$\varepsilon=$ error

Kinerja Perusahaan diukur dengan menggunakan rasio return on asset (ROA) dan Tobin's $q$ yang dikonotasikan dengan $\mathrm{Y}_{1}$ dan $\mathrm{Y}_{2}$. Return on asset (ROA) merupakan rasio untuk mengukur kemampuan perusahaan untuk menghasilkan laba bersih berdasarkan tingkat asset yang tertentu. Rasio ini dapat dihitung sebagai berikut, Kasmir (2008:84).

\section{$\mathrm{ROA}=$ Laba Bersih/Total Aset}

Tobin's $q$ adalah rasio nilai pasar aset perusahaan yang diukur dengan nilai pasar dari saham yang beredar dan utang dengan biaya penggantian aset perusahaan Tobin (1969:29). Semakin tinggi nilai pasar perusahaan dibandingkan modalnya maka semakin banyak kelebihan yang dianggap sebagai laba. Tobin's $q$ dapat di hitung menggunakan rumus sebagai berikut: (Sudiyatno, B., dan Puspitasari, E. (2010).

$\mathrm{q}=(\mathrm{MVS}+\mathrm{MVD}) / \mathrm{RVA}$

di mana:

MVS = Market value of all outstanding stock

MVD = Market value of all debt

$\mathrm{RVA}=$ Replacement value of all production capacity

Seluruh data yang digunakan dalam penelitian ini adalah data kuantitatif. Jenis data yang digunakan dalam penelitian ini adalah data sekunder, sedangkan sumber data yang dijadikan sampel dalam penelitian ini diperoleh dari laporan keuangan triwulanan perusahaan manufaktur yang terdaftar di BEI pada tahun 2008-2012. Pengamatan manajemen laba akrual ini di lakukan mulai tahun 2008-2012 untuk memenuhi rumus t-1 maka data yang dikumpulkan mengenai laporan keuangannya yaitu dimulai pada tahun 2007-2012.

Metode pengumpulan data yang digunakan dalam penelitian ini adalah dengan cara dokumentasi yaitu pengumpulan data kuantitatif dengan melihat atau menganalisis dokumen-dokumen yang dibuat oleh subjek sendiri atau oleh orang lain tentang subjek. Data bersumber dari www.idx.co.id dalam bentuk laporan keuangan triwulanan perusahaan dan juga bersumber dari ICMD (Indonesian Capital Market Directory).

Perhitungan statistik dalam penelitian ini menggunakan program SPSS (Statistic Program for Social Science) 16.0 for windows. Teknik analisis data yang digunakan adalah analisis deskriptif data, uji asumsi klasik, dan analisis regresi sederhana untuk menguji pengaruh manajemen laba akrual terhadap kinerja perusahaan melalui pendekatan Revenue Discretionary.

Pengujian hipotesis di bahas dengan uji Regresi Linear Sederhana (Simple Linear Regression), dengan perumusan hipotesis sebagai berikut:

H 1: Ada pengaruh manajemen laba akrual dengan pendekatan Revenue Model terhadap kinerja perusahaan yang diukur menggunakan Return On Asset (ROA).

$\mathrm{H}_{\mathrm{b}}$ : Ada pengaruh manajemen laba akrual dengan Pendekatan Conditional Revenue Model terhadap kinerja perusahaan yang diukur menggunakan Return On Asset (ROA).

H 2 : Ada pengaruh manajemen laba akrual dengan pendekatan Revenue Model terhadap kinerja perusahaan yang diukur menggunakan Tobin's $q$.

$\mathrm{H} 2_{\mathrm{b}}$ : Ada pengaruh manajemen laba akrual dengan pendekatan Conditional Revenue Model terhadap kinerja perusahaan yang diukur menggunakan Tobin's $q$.

Penelitian ini melakukan dua kali analisis regresi yaitu yang pertama untuk menganalisis dalam mencari pembuktian adanya praktik manajemen laba dengan mencari error. Analasis yang kedua yaitu melakukan Analisis regresi yang digunakan untuk menguji pengaruh variabel independen manajemen laba akrual melalui pendekatan Revenue Discretionary terhadap variabel dependen kinerja perusahaan yang diukur dengan ROA dan Tobin's q. Analisis ini secara matematis ditulis dengan persamaan sebagai berikut.

Model 1

$\mathrm{ROA}=\alpha+\beta_{1} \mathrm{MLA}_{\text {stub (RM) }}+\varepsilon$

Model 2

$\mathrm{ROA}=\alpha+\beta_{1} \mathrm{MLA}_{\text {stub (CRM) }}+\varepsilon$

Model 3

$T q=\alpha+\beta_{1} \mathrm{MLA}_{\text {stub (RM) }}+\varepsilon$ 
Tabel 1. Frekuensi Perusahaan yang Melakukan MLA

\begin{tabular}{lcccc}
\hline \multicolumn{1}{c}{ Nilai Residual } & $\begin{array}{c}\text { Jumlah Perusahaan Terindikasi } \\
\text { Melakukan MLA }\end{array}$ & Percent & Valid Percent & Cumulative Percent \\
\hline$<-0.075$ & 107 & 46.3 & 46.3 & 46.3 \\
$>-0.075<0.075$ & 53 & 22.9 & 22.9 & 69.3 \\
$>0.075$ & 71 & 30.7 & 30.7 & 100.0 \\
Total & 231 & 100.0 & 100.0 & \\
\hline
\end{tabular}

Sumber : Hasil olahan SPSS

Tabel 2. Frekuensi Perusahaan yang Melakukan MLA

\begin{tabular}{lcccc}
\hline Nilai Residual & $\begin{array}{c}\text { Jumlah Perusahaan Terindikasi } \\
\text { Melakukan MLA }\end{array}$ & Percent & Valid Percent & Cumulative Percent \\
\hline$<-0.075$ & 71 & 19.0 & 19.0 & 19.0 \\
$>-0.075<0.075$ & 38 & 10.2 & 10.2 & 29.1 \\
$>0.075$ & 265 & 70.9 & 70.9 & 100.0 \\
Total & 374 & 100.0 & 100.0 & \\
\hline
\end{tabular}

Sumber: Hasil olahan SPSS

Model 4

$T q=\alpha+\beta_{1} \mathrm{MLA}_{\text {stub (CRM) }}+\varepsilon$

di mana :

$$
\begin{aligned}
& T q \quad=\text { Tobin's } q \\
& \text { ROA }=\text { Return On Asset's } \\
& \alpha \quad=\text { Konstanta } \\
& \beta_{1} \mathrm{MLA}_{\text {stub (RM) }}=\text { Manajemen Laba Akrual Model } \\
& \text { Stubben (Revenue Model) } \\
& \beta_{1} \mathrm{MLA}_{\text {stub (CRM) }}=\text { Manajemen Laba Akrual Model } \\
& \text { Stubben (Conditional Revenue } \\
& \text { Model) } \\
& \beta_{1} \quad=\text { Koefisien regresi } \text { MLA }_{\text {Stub }} \\
& \varepsilon \quad=\text { error term }
\end{aligned}
$$

\section{HASIL}

\section{Manajemen Laba Akrual (X)}

Pola perusahaan dalam melakukan manajemen laba dalam pengukuran Stubben adalah dengan cara memajukan pengakuan pendapatan yang dapat dilakukan dengan menggunakan FOB Shipping Point. FOB Shipping Point adalah metode pengakuan transaksi penjualan dengan cara mengakui pendapatan terlebih dahulu tanpa memperhitungkan bahwa barang tersebut telah sampai pada konsumen ataupun belum. Dalam hal ini, perusahaan dapat memajukan pendapatan untuk tahun berikutnya ke tahun berjalan untuk memperbesar laba yang dihasilkan. Berikut uraian penjelasan untuk masing-masing formula dalam mendeteksi manajemen laba melalui nilai residual yang dihasilkan.

\section{Revenue Model}

Penelitian ini mengacu pada penelitian yang dilakukan oleh Roychowdhury (2004) untuk mengukur terjadinya manajemen laba. Penelitian tersebut mengukur adanya indikasi praktik manajemen laba riil dengan menggunakan nilai residual. Nilai residual tersebut adalah nilai error dengan interval yang kurang dari -0.075 dan melebihi $0.075(\varepsilon<-0.075$ atau $\varepsilon>0.075$ ) mengindikasikan terjadinya praktik manajemen laba. Saat dilakukan pengujian pada formula Revenue Model (Tabel 1.) nilai yang kurang dari -0.075 adalah sebanyak 107 (46.3\%) sampel dan nilai yang melebihi 0.075 sebanyak 71 (30.7\%). Jika digabungkan terdapat $77 \%$ dari 231 sampel yang terindikasi melakukan manajemen laba dan hanya $71(30.7 \%)$ saja yang tidak terindikasi melakukan manajemen laba dari seluruh sampel yang diuji.

\section{Conditional Revenue Model}

Berdasarkan pengujian terhadap formula Conditional Revenue Model (Tabel 2.), terdapat $265(70.9 \%)$ sampel yang memiliki nilai lebih dari 0.075 dan kurang dari -0.075 sebesar 71 (19\%) sampel terindikasi melakukan praktek manajemen 
laba dan hanya 38 (10.2\%) sampel yang tidak terindikasi melakukan praktek manajemen laba. Apabila nilai yang kurang dari -0.075 dan melebihi 0.075 digabungkan, maka persentase yang terindikasi melakukan praktek manajemen laba adalah $89.9 \%$ dari 374 sampel yang diteliti. Hal tersebut dapat disimpulkan bahwa praktek manajemen laba terindikasi lebih tinggi pada perhitungan Conditional Revenue Model dibandingkan dengan perhitungan menggunakan Revenue Model.

\section{Kinerja Perusahaan (Return On Asset)}

Kinerja perusahaan yang diukur menggunakan Return On Asset (ROA) memiliki nilai rata-rata tertinggi pada sektor industri Cement yaitu sebesar 0,16 dalam kurun waktu 2009 hingga 2012. Nilai minimum nilai rata-rata Return On Asset terdapat pada sektor industri Lumber and Wood yaitu sebesar $-0,06$. Hal ini menjelaskan bahwa sektor industri Cement pada kurun waktu 2009 hingga tahun 2012 memiliki tingkat efisiensi yang cukup baik dalam meningkatkan laba bersih dan pengelolaan manajemennya. Namun sebaliknya yang dialami pada sektor industri Lumber and Wood adalah kurangnya tingkat efisiensi dalam meningkatkan laba dan pengelolaan manajemennya sehingga membuat angka Return On Asset menjadi negatif.
Terdapatnya perbedaan antara jumlah frekuensi sampel yang digunakan pada masing formula menyebabkan penyesuaian kembali atas jumlah variabel dependen yang akan di pengaruhkan terhadap masing-masing formula. Maka dalam pengujian mengenai variabel akan dilakukan dua kali.

Tabel 4. merupakan hasil pengujian per sektor industri. Dari tabel tersebut dapat dijelaskan bahwa sektor yang diuji memiliki frekuensi yang lebih banyak dibandingkan dengan formula pertama (Revenue Model). Terdapat 18 sektor industri dari 19 sektor industri manufaktur yang dapat diuji. Sektor industri tersebut adalah Photographic Equipment yang secara otomatis terseleksi karena tidak memenuhi kriteria pengambilan sampel. Kinerja perusahaan yang diukur menggunakan Return On Asset memiliki nilai rata-rata tertinggi tetap seperti pada pengujian sebelumnya (Tabel 4.) yaitu pada sektor industri Cement yang pada tabel ini memiliki nilai sebesar 0,13 dalam kurun waktu 2008-2011. Dapat disimpulkan dari Tabel 3. dan Tabel 4. bahwa dari tahun 2008 hingga tahun 2012 sektor industri Cement dapat mengelola manajemennya dengan baik sehingga nilai pengembalian asetnya menjadi sangat baik dibandingkan sektor industri lain.

Tabel 3. Uji Deskriptif Return On Asset Berdasarkan Sektor Industri

\begin{tabular}{|c|c|c|c|c|c|c|}
\hline No. & Sektor Industri & $\mathbf{N}$ & Min & Max & Mean & Std Deviasi \\
\hline 1 & Adhesive & 7 & $-0,13$ & 0,46 & 0,09 & 0,19 \\
\hline 2 & Apparel and Other Textile Products & 12 & $-0,06$ & 0,12 & 0,05 & 0,05 \\
\hline 3 & Automotive and Allied Products & 28 & 0,01 & 0,22 & 0,09 & 0,06 \\
\hline 4 & Cables & 8 & 0,03 & 0,11 & 0,06 & 0,03 \\
\hline 5 & Cement & 6 & 0,08 & 0,21 & 0,16 & 0,06 \\
\hline 6 & Chemical and Allied & 14 & 0,00 & 0,28 & 0,07 & 0,07 \\
\hline 7 & Electronic and Office Equipment & 8 & 0,01 & 0,41 & 0,08 & 0,14 \\
\hline 8 & Food and Beverages & 43 & $-0,04$ & 0,28 & 0,11 & 0,07 \\
\hline 9 & Lumber and Wood Products & 4 & $-0,18$ & 0,00 & $-0,06$ & 0,09 \\
\hline 10 & Metal and Allied Products & 24 & $-0,05$ & 0,32 & 0,06 & 0,08 \\
\hline 11 & Paper and Allied Products & 9 & $-0,08$ & 0,12 & 0,02 & 0,06 \\
\hline 12 & Pharmaceuticals & 14 & 0,02 & 0,39 & 0,15 & 0,11 \\
\hline 13 & Plastics and Glass Products & 24 & $-0,75$ & 0,16 & $-0,03$ & 0,23 \\
\hline 14 & Stone, Clay, Glass and Concrete Products & 6 & $-0,01$ & 0,22 & 0,12 & 0,08 \\
\hline 15 & Textile Mill Products & 10 & $-0,16$ & 0,10 & $-0,02$ & 0,16 \\
\hline \multirow[t]{3}{*}{16} & Tobacco Manufacturers & 10 & $-0,05$ & 0,41 & 0,15 & \\
\hline & Max & & 0,08 & 0,5 & 0,16 & \\
\hline & Min & & $-0,7$ & 0,001 & $-0,06$ & \\
\hline
\end{tabular}

Sumber: Hasil olahan SPSS 
Tabel 4. Uji Deskriptif Return On Asset Berdasarkan Sektor Industri

\begin{tabular}{rlrrrrr}
\hline No. Sektor Industri & \multicolumn{1}{c}{ N } & Min & Max & Mean & Std Deviasi \\
\hline 1 & Adhesive & 8 & $-0,15$ & 0,2 & 0,01 & 0,12 \\
2 & Apparel and Other Textile Products & 32 & $-0,72$ & 0,13 & $-0,02$ & 0,15 \\
3 & Automotive and Allied Products & 51 & $-0,09$ & 0,21 & 0,07 & 0,06 \\
4 & Cables & 20 & $-0,01$ & 0,15 & 0,03 & 0,03 \\
5 & Cement & 8 & 0,03 & 0,21 & 0,13 & 0,06 \\
6 & Chemical and Allied & 22 & $-0,43$ & 1,47 & 0,12 & 0,33 \\
7 & Consumer Goods & 6 & 0,05 & 0,12 & 0,08 & 0,33 \\
8 & Electronic and Office Equipment & 6 & $-0,06$ & 0,1 & 0 & 0,06 \\
9 & Fabricated Metal Products & 8 & $-0,06$ & 0,04 & 0,01 & 0,03 \\
10 & Food and Beverages & 52 & $-0,14$ & 0,4 & 0,1 & 0,09 \\
11 & Lumber and Wood Products & 8 & $-0,2$ & 0,03 & $-0,04$ & 0,08 \\
12 & Metal and Allied Products & 43 & $-0,1$ & 0,3 & 0,05 & 0,07 \\
13 & Paper and Allied Products & 13 & $-0,6$ & 0,14 & $-0,04$ & 0,2 \\
14 & Pharmaceuticals & 29 & 0 & 0,4 & 0,11 & 0,1 \\
15 & Plastics and Glass Products & 43 & $-0,75$ & 0,15 & $-0,02$ & 0,17 \\
16 & Stone, Clay, Glass and Concrete Products & 5 & 0,07 & 0,11 & 0,08 & 0,02 \\
17 & Textile Mill Products & 16 & $-0,65$ & 0,5 & $-0,14$ & 0,23 \\
18 & Tobacco Manufacturers & 4 & 0 & 0,05 & 0,03 & 0,02 \\
& Max & & 0,07 & 1,47 & 0,13 & $-0,14$ \\
\hline
\end{tabular}

Sumber: Hasil olahan SPSS

Dalam Tabel 4. tampak bahwa nilai rata-rata terendah terdapat pada sektor industri Textile Mill Products. Nilai rata-rata atas tingkat pengembalian assetnya sebesar-0,14 dalam kurun waktu tahun 2008 hingga tahun 2012. Dapat disimpulkan bahwa dalam kurun waktu tahun 2008 hingga 2009, sektor industri Textile Mill Products memiliki tingkat efisiensi pengelolaan laba dan manajemen yang kurang baik.

\section{Kinerja Perusahaan (Tobin's q)}

Pengujian kinerja perusahaan yang diukur dengan menggunakan Tobin's q per sektor industri pada tabel 5 terlihat bahwa nilai rata-rata tertinggi terdapat pada sektor Paper and Allied Products yaitu sebesar 0,43 . Pada sektor industri Cables memiliki nilai yang cukup rendah yaitu sebesar 0,04 . Penjelasan diatas dapat disimpulkan bahwa sektor Paper and Allied Product memiliki nilai pasar yang cukup baik diantara sektor industri lain pada perusahaan manufaktur, berbeda dengan sektor industri Cables yang memiliki nilai pasar yang paling rendah dibandingkan sektorsektor lainnya. Akan tetapi dalam kalimat interpretasi yang diungkapkan oleh Lindenberg \& Ross (1981) dalam Sudiyatno \& Puspitasari (2010), apabila nilai Tobin's $q$ kurang dari $1(<1)$ maka dapat dijelaskan bahwa saham dalam kondisi undervalued ataupun pengelolaan aktiva yang buruk oleh manajemen sehingga investor enggan menanamkan modalnya karena laba yang sedikit akan berpengaruh terhadap pembagian deviden yang berarti rendahnya nilai pasar perusahaan tersebut. Berdasarkan penjelasan tersebut dapat disimpulkan bahwa dalam pengujian ini tidak terdapat sektor industri yang memiliki nilai pasar yang cukup baik, karena berdasarkan tabel 5 tidak ada nilai rata-rata Tobin's $q$ perusahaan persektor industri manufaktur yang memiliki nilai sama dengan satu (=1) maupun lebih dari satu $(>1)$. Namun apabila dilihat perperusahaan, maka pada kolom maksimum nilai Tobin's $q$ tertinggi dimiliki oleh sektor industri Metal and Allied Products sebesar 2,37. Nilai tersebut dimiliki oleh PT Jakarta Kyoei Steel Works Tbk pada tahun 2012, hal ini menggambarkan bahwa saham perusahaan tersebut dalam kondisi overvalued yang berarti manajemen berhasil dalam mengelola aktiva perusahaan dan potensi pertumbuhan investasi tinggi (Lindenberg \& Ross (1981) dalam Sudiyatno \& Puspitasari, 2010). Nilai terendah terdapat pada perusahaan PT Tembaga Mulia Semanan Tbk ditahun 2010 pada sektor industri Metal and Allied Products dengan hasil Tobin's $q$ sebesar 0,00 
Tabel 5. Daftar Uji Deskriptif Untuk Tobin's Q Berdasarkan Sektor Industri

\begin{tabular}{lllllll}
\hline No. Sektor Industri & \multicolumn{1}{c}{ N } & N & Max & Mean & Std Deviasi \\
\hline 1 & Adhesive & 7 & 0,07 & 0,18 & 0,14 & 0,5 \\
2 & Apparel and Other Textile Products & 12 & 0,03 & 0,57 & 0,21 & 0,22 \\
3 & Automotive and Allied Products & 28 & 0,04 & 0,61 & 0,19 & 0,13 \\
4 & Cables & 8 & 0,02 & 0,07 & 0,04 & 0,02 \\
5 & Cement & 6 & 0,10 & 0,26 & 0,17 & 0,06 \\
6 & Chemical and Allied & 14 & 0,04 & 0,29 & 0,17 & 0,8 \\
7 & Electronic and Office Equipment & 8 & 0,06 & 0,41 & 0,17 & 0,1 \\
8 & Food and Beverages & 43 & 0,04 & 0,73 & 0,21 & 0,14 \\
9 & Lumber and Wood Products & 4 & 0,12 & 0,34 & 0,26 & 0,09 \\
10 & Metal and Allied Products & 24 & 0,00 & 2,37 & 0,39 & 0,75 \\
11 & Paper and Allied Products & 9 & 0,16 & 1,27 & 0,43 & 0,33 \\
12 & Pharmaceuticals & 14 & 0,04 & 0,27 & 0,10 & 0,7 \\
13 & Plastics and Glass Products & 24 & 0,01 & 1,13 & 0,21 & 0,3 \\
14 & Stone, Clay, Glass and Concrete Products & 6 & 0,10 & 0,71 & 0,32 & 0,3 \\
15 & Textile Mill Products & 10 & 0,05 & 0,72 & 0,29 & 0,22 \\
16 & Tobacco Manufacturers & 10 & 0,02 & 0,45 & 0,14 & 0,15 \\
& Max & & & 0,16 & 2.31 & 0,43 \\
& Min & & 0,00 & 0,07 & 0,04 \\
\hline
\end{tabular}

Sumber: Hasil olahan SPSS

Tabel 6. Daftar Uji Deskriptif Untuk Tobin’s Q Berdasarkan Sektor Industri

\begin{tabular}{llrrrrr}
\hline No. Sektor Industri & \multicolumn{1}{c}{ N } & Min & Max & Mean & Std Deviasi \\
\hline 1 & Adhesive & 8 & 0,02 & 0,18 & 0,1 & 0,06 \\
2 Apparel and Other Textile Products & 32 & 0,02 & 2,9 & 0,41 & 0,68 \\
3 & Automotive and Allied Products & 51 & 0,01 & 0,53 & 0,16 & 0,12 \\
4 & Cables & 20 & 0,01 & 0,26 & 0,06 & 0,07 \\
5 & Cement & 8 & 0,09 & 0,52 & 0,23 & 0,16 \\
6 & Chemical and Allied & 22 & 0,03 & 0,3 & 0,16 & 0,07 \\
7 & Consumer Goods & 6 & 0,02 & 0,12 & 0,06 & 0,04 \\
8 & Electronic and Office Equipment & 6 & 0,01 & 0,15 & 0,08 & 0,05 \\
9 & Fabricated Metal Products & 8 & 0,03 & 0,17 & 0,1 & 0,06 \\
10 & Food and Beverages & 52 & 0,03 & 0,92 & 0,27 & 0,2 \\
11 & Lumber and Wood Products & 8 & 0,12 & 0,38 & 0,3 & 0,08 \\
12 & Metal and Allied Products & 43 & 0 & 2,4 & 0,32 & 0,65 \\
13 & Paper and Allied Products & 13 & 0,14 & 1,4 & 0,64 & 0,4 \\
14 & Pharmaceuticals & 29 & 0,03 & 0,41 & 0,11 & 0,11 \\
15 & Plastics and Glass Products & 43 & 0 & 1,13 & 0,16 & 0,18 \\
16 & Stone, Clay, Glass and Concrete Products & 5 & 0,13 & 0,52 & 0,3 & 0,15 \\
17 & Textile Mill Products & 16 & 0,1 & 1,4 & 0,72 & 0,4 \\
18 & Tobacco Manufacturers & 4 & 0,05 & 0,44 & 0,3 & 0,17 \\
& Max & & 0,14 & 2,9 & 0,72 & 0,06 \\
\hline
\end{tabular}

Sumber: Hasil olahan SPSS 
Guna menyesuaikan jumlah populasi yang digunakan dalam formula kedua yaitu Conditional Revenue Model, maka dibuat Tabel 6. untuk memudahkan dalam menganalisa uji deskriptif terhadap Tobin's $q$.

Dalam pengujian persektor industri pada Tabel 6. dapat dilihat nilai tertinggi dalam rata-rata pengukuran nilai pasar perusahaan (Tobin's q) yaitu terdapat pada sektor industri Textile Mill Products yaitu sebesar 0,72 . Nilai tersebut cukup tinggi dibandingkan dengan nilai yang dimiliki sektor industri lain. Meskipun nilai yang dimiliki oleh sektor industri Textile Mill Products paling tinggi dibandingkan sektor industri yang lainnya, akan tetapi nilai tersebut kurang dari satu $(<1)$ yang menggambarkan bahwa saham dalam kondisi undervalued yang berarti bahwa manajemen telah gagal dalam mengelola aktiva perusahaan dan potensi pertumbuhan investasi rendah (Lindenberg \& Ross, 1981 dalam Sudiyatno \& Puspitasari, 2010).

Dari interpretasi Tabel 6. dapat disimpulkan bahwa tidak terdapat sektor industri manufaktur yang memiliki kondisi saham yang overvalued. Apabila dilihat per perusahaan maka dapat dilihat pada kolom maksimum yaitu yang memiliki hasil nilai perhitungan Tobin's $q$ tertinggi dimiliki oleh sektor Apparel and Other Textile Products yaitu sebesar 2,9 yang dimiliki oleh PT Primarindo Asia Infrastructure Tbk pada tahun 2010. Hal tersebut menggambarkan bahwa saham perusahaan tersebut dalam kondisi overvalued. Manajemen berhasil dalam mengelola aktiva perusahaan dan potensi pertumbuhan investasi tinggi (Lindenberg \& Ross, 1981 dalam Sudiyatno \& Puspitasari, 2010). Nilai terendah terdapat pada perusahaan PT Tembaga Mulia Semanant Tbk di tahun 2008 pada sektor industri Metal and Allied Products dengan hasil Tobin's $q$ sebesar 0,00. Dari hasil tabulasi, nilai Tobin's $q$ pada PT Tembaga Mulia Semanan Tbk dari tahun ke tahun tidak mengalami kenaikan yang signifikan sehingga akan selalu terlihat 0,00 .

\section{PEMBAHASAN}

Untuk melihat pengaruh dari variabel independen terhadap variabel dependen digunakan uji $\mathrm{t}$ dengan melihat hasil signifikansi yang dihasilkan harus kurang dari 0.05. Dalam penelitian ini terdapat empat model regresi yaitu 1) MLA Stubben-ROA (Revenue Model). 2) MLA Stubben-Tobim's q (Revenue Model). 3) MLA
Stubben-ROA (Conditional Revenue Model). 4) MLA Stubben-Tobim 's q (Conditional Revenue Model).

Hasil perhitungan uji tpada keseluruhan hipotesis menunjukkan bahwa hanya hipotesis $\mathrm{H}_{\mathrm{b}}$ yang berbunyi "Manajemen laba akrual melalui formula Conditional Revenue Model berpengaruh terhadap Return On Asset" dengan nilai signifikansi sebesar 0.014. Namun pengujian regresi tidak berpengaruh secara parsial terhadap tiga hipotesis lainnya.

Untuk mengetahui secara detail dalam hasil uji regresi pada kedua formula, maka dilakukan pengujian satu persatu sektor industri yang masuk dalam sampel. Berdasarkan pengujian pada Revenue Model, hasil uji nampak bahwa hanya terdapat dua sektor industri yang memiliki nilai signifikansi dibawah 0.05 yaitu sektor industri Plastics and Glass Products sebesar 0.015 dan Textile Mill Products sebesar 0.049. Sehingga hipotesis $\mathrm{H} 1_{\mathrm{a}}$ dalam penelitian ini diterima hanya pada sektor industri Plastics and Glass Products dan Textile Mill Products.

Pengujian per sektor industri untuk mencari nilai signifikansi pada hipotesis $\mathrm{H} 2$ a didapatkan hasil bahwa Pengujian persektor atas formula pertama yaitu Revenue Model, memberikan hasil bahwa terdapat dua sektor perusahaan manufaktur yang memiliki nilai signifikansi lebih rendah dari 0.05 atau sebesar 5\%. Kedua sektor industri tersebut adalah sektor industri Plastics and Glass Products dan sektor industri Chemical and Allied dengan nilai signifikansi masing-masing sebesar 0.015 dan 0.047. Pada pengujian regresi per sektor perusahaan manufaktur untuk formula Conditional Revenue Model (hipotesis $\mathrm{H} 2_{\mathrm{b}}$ ), hasil yang signifikan hanya terdapat pada sektor industri Textile Mill Products yaitu dengan nilai signifikansi sebesar 0,049 .

Dari uraian diatas dapat disimpulkan bahwa hipotesis kedua dalam penelitian ini diterima hanya pada tiga sektor industri ini saja yaitu sektor industri Chemical and Allied, Plastics and Glass Products, dan pada sektor industri Textile Mill Products dengan penjabaran bahwa dua sektor industri Chemical and Allied dan Plastics and Glass Products didapat dari hasil memproksikan antara manajemen laba akrual yang dihitung menggunakan Revenue Model dengan Tobin's $q$ dan satu sektor industri yaitu Textile Mill Products yang didapat dari hasil memproksikan antara manajemen laba akrual yang dihitung menggunakan Conditional Revenue Model dengan Tobin's q. Untuk mempermudah analisis dapat dilihat pada Tabel 7. 
Tabel 7. Hasil Uji Hipotesis

\begin{tabular}{|c|c|c|c|c|c|c|c|c|c|c|c|c|}
\hline \multirow[b]{3}{*}{ Sektor Industri } & \multicolumn{6}{|c|}{ Model 1 (Revenue Model) } & \multicolumn{6}{|c|}{ Model 2 (Conditional Revenue Model) } \\
\hline & \multicolumn{3}{|c|}{$\begin{array}{l}\text { Return On Asset } \\
\text { (ROA) }\end{array}$} & \multicolumn{3}{|c|}{ Tobin's q } & \multicolumn{3}{|c|}{$\begin{array}{l}\text { Return On Asset } \\
\text { (ROA) }\end{array}$} & \multicolumn{3}{|c|}{ Tobin's q } \\
\hline & $\mathbf{R}^{2}$ & t hit & Sig & $\mathbf{R}^{2}$ & t hit & sig & $\mathbf{R}^{2}$ & t hit & Sig & $\mathbf{R}^{2}$ & t hit & sig \\
\hline Adhesive & 0.00 & 0.016 & 0.99 & 0.00 & -0.062 & 0.95 & 0.76 & 4.385 & 0.00 & 0,14 & $-0,991$ & 0,36 \\
\hline Apparel and Other Textile Products & 0.02 & 1.741 & 0.11 & 0.01 & -0.328 & 0.75 & 0.34 & 3.914 & 0.00 & 0,00 & 0.143 & 0,88 \\
\hline Automotive and Allied Products & 0.00 & 0.072 & 0.94 & 0.00 & 0.336 & 0.74 & 0.00 & 0.296 & 0.77 & 0,05 & $-1,559$ & 0,12 \\
\hline Cables & 0.00 & -0.064 & 0.95 & 0.13 & -0.952 & 0.38 & 0.01 & 0,345 & 0.73 & 0,00 & 0,167 & 0,87 \\
\hline Cement & 0.09 & 0.642 & 0.56 & 0.05 & -0.453 & 0.67 & 0.01 & 0,279 & 0.79 & 0,00 & $-0,172$ & 0,87 \\
\hline Chemical and Allied & 0.00 & 0.095 & 0.93 & 0.29 & 2.214 & 0.05 & 0.25 & $-2,578$ & 0.02 & 0,00 & $-0,060$ & 0,95 \\
\hline Consumer Goods & 0.34 & 1.756 & 0.13 & 0.01 & -0.257 & 0.80 & 0.34 & $-0,143$ & 0.22 & 0,03 & $-0,336$ & 0,75 \\
\hline Electronic and Office Equipment & 0.02 & 0.922 & 0.36 & 0.02 & -0.885 & 0.38 & 0.04 & 0,425 & 0.69 & 0,00 & $-0,052$ & 0,96 \\
\hline Fabricated Metal Products & 0.06 & -0.370 & 0.75 & 0.14 & -0.562 & 0.63 & 0.62 & 3,164 & 0.02 & 0,00 & $-0,094$ & 0,93 \\
\hline Food and Beverages & 0.02 & -0.738 & 0.47 & 0.01 & -0.382 & 0.71 & 0.00 & 0,029 & 0.98 & 0,00 & $-0,221$ & 0,83 \\
\hline Lumber and Wood Products & 0.02 & 0.424 & 0.68 & 0.03 & -0.487 & 0.64 & 0.51 & 2,506 & 0.05 & 0,01 & $-0,298$ & 0,78 \\
\hline Metal and Allied Products & 0.02 & -1.275 & 0.23 & 0.16 & 1.500 & 0.16 & 0.00 & $-0,368$ & 0.71 & 0,03 & $-1,140$ & 0,26 \\
\hline Paper and Allied Products & 0.25 & -2.65 & 0.01 & 0.25 & 2.637 & 0.02 & 0.00 & $-0,242$ & 0.81 & 0,03 & 0,540 & 0,60 \\
\hline Pharmaceuticals & 0.1 & 0.66 & 0.55 & 0.09 & -0.621 & 0.57 & 0.02 & 0,722 & 0.48 & 0,00 & 0,089 & 0,93 \\
\hline Plastics and Glass Products & 0.4 & -2.3 & 0.05 & 0.00 & 0.106 & 0.92 & 0.02 & 0,996 & 0.32 & 0,04 & 1,245 & 0,22 \\
\hline $\begin{array}{l}\text { Stone, Clay, Glass and Concrete } \\
\text { Products }\end{array}$ & 0.01 & 0.27 & 0.79 & 0.05 & -0.624 & 0.55 & 0.01 & 0,143 & 0.89 & 0,77 & $-3,215$ & 0,05 \\
\hline Textile Mill Products & & & & & & & 0.03 & 0,516 & 0.52 & 0,14 & $-1,518$ & 0,15 \\
\hline Tobacco Manufacturers & & & & & & & 0.38 & $-1,109$ & 0.38 & 0,07 & $-0,391$ & 0,73 \\
\hline
\end{tabular}

\section{KESIMPULAN}

Penelitian ini bertujuan untuk menguji pengaruh dari manajemen laba akrual dengan pendekatan Revenue Discretionary terhadap kinerja perusahaan yang diukur dengan menggunakan Return On Asset (ROA) dan Tobin's q. Dalam pendekatan tersebut, terdapat dua formula untuk mendeteksi indikasi praktek manajemen laba pada perusahaan yaitu Revenue Model dan Conditional Revenue Model yang akan di proksikan terhadap kinerja perusahaan yang diukur dengan menggunakan Return On Asset dan Tobin's $q$.

Pada perhitungan uji t secara keseluruhan antara hasil perhitungan formula Revenue Model yang diproksikan terhadap kinerja perusahaan (ROA) tidak berpengaruh. Sebaliknya untuk hasil pengujian dari formula Conditional Revenue Model terhadap kinerja perusahaan (ROA) berpengaruh secara parsial. sedangkan untuk pengujian manajemen laba dengan pendekatan Revenue Discretionary terhadap kinerja perusahaan yang diukur menggunakan Tobin's $q$ tidak berpengaruh secara parsial. Pada pengujian persektor industri yang diproksikan terhadap Return On Asset didapat hanya pada sektor industri Plastics and Glass Products, Apparel and Other Textile Products, Chemical and Allied, dan Textile Mill Products, yang berpengaruh secara parsial terhadap manajemen laba akrual dengan pendekatan Revenue Discretionary dan untuk pengujian terhadap Tobin's $q$ hanya pada sektor industri Chemical and Allied, Plastics and Glass Products, dan Textile Mill Products yang berpengaruh secara parsial terhadap manajemen laba akrual dengan pendekatan Revenue Discretionary.

Pada pengujian $\mathrm{R}^{2}$, hanya model tiga yang memiliki hasil yang paling tinggi yaitu sebesar 0.016 
atau sebesar 1.6\% manajemen laba dengan formula Conditional Revenue Model mampu menerangkan variasi variabel terikat yaitu Return On Asset dan sebesar 0.984 atau sebesar 98.4\% dijelaskan oleh variabel lain. Sedangkan pada model satu, dua dan empat memilki nilai $\mathrm{R}^{2}$ yang cukup rendah yaitu $0.3 \%$, $0 \%$, dan $0.1 \%$. Hal tersebut berarti variabel Return On Asset dan Tobin's $q$ tidak dapat dijelaskan oleh variabel manajemen laba akrual dengan pendekatan Revenue Discretionary.

Tidak ada pengaruh manajemen laba akrual dengan pendekatan Revenue Model terhadap kinerja perusahaan yang diukur menggunakan Return On $\operatorname{Asset}\left(\mathrm{H}_{0} 1_{\mathrm{a}}\right.$ diterima $)$.

Ada pengaruh manajemen laba akrual dengan Pendekatan Conditional Revenue Model terhadap kinerja perusahaan yang diukur menggunakan Return On Asset ( $\mathrm{H}_{1} 1_{\mathrm{b}}$ diterima).

Tidak ada pengaruh manajemen laba akrual dengan pendekatan Revenue Model terhadap kinerja perusahaan yang diukur menggunakan Tobin's $q\left(\mathrm{H}_{0} 2_{\mathrm{a}}\right.$ diterima).

Tidak ada pengaruh manajemen laba akrual dengan pendekatan Conditional Revenue Model terhadap kinerja perusahaan yang diukur menggunakan Tobin's $q\left(\mathrm{H}_{0} 2_{\mathrm{b}}\right.$ diterima $)$.

Peneliti menyadari bahwa masih banyak kekurangan dalam penelitian ini, oleh karena itu berikut ini merupakan uraian keterbatasan dan saran yang ada pada penelitian ini. Semoga uraian dibawah ini dapat bermanfaat bagi penelitian selanjutnya. 1) Pada penelitian ini untuk formula Revenue Model sampel yang digunakan adalah laporan keuangan triwulanan yang jarang sekali diterbitkan sehingga memperkecil jumlah sampel yang didapat. 2) Penelitian ini menggunakan data yang tidak berdistribusi normal. Akan tetapi analisis tetap dapat dilanjutkan. 3) Penelitian ini tidak mempertimbangkan perubahan regulasi atas PSAK 1 tahun 2009 yang mulai berlaku Januari tahun 2011 sehingga untuk formula Conditional Revenue Model hanya meneliti hingga tahun 2011 saja. Melihat adanya keterbatasan yang ada, maka peneliti mengajukan beberapa saran sebagai berikut: 1) Untuk setiap perusahaan yang terdaftar di bursa efek Indonesia sebaiknya menyajikan laporan keuangan triwulanan agar lebih bersifat terbuka dan dapat dijadikan bahan penelitian oleh pihak yang berkepentingan. 2) Bagi peneliti selanjutnya diharapkan mempertimbangkan sampel yang akan digunakan agar lebih mudah untuk melakukan analisis.

\section{DAFTAR PUSTAKA}

Dechow,P.,\&Skinner,D.2000. Earnings Management: Reconciling the Views of Accounting Academics, Practitioners and Regulators. Accounting Horizon, 14: 235-250.

Gunny, K. 2005. What are the Consequences of real Earnings Management?. www.papers.ssrn.com. (diakses Tanggal 06 Desember 2010).

IAI. 2009. PSAK 1. Jakarta: Salemba Empat.

Jensen, M., \& Meckling, W. 1976. Theory of the Firm: Managerial Behaviour, Agency Cost and Ownership Structure. Journal of Financial Economics, 3(4): 185-196.

Kasmir. 2008. Analisis Laporan Keuangan. Jakarta: Rajawali Pers.

Parsaoran, D. 2009. Skanda; Manipulasi Laporan Keuangan PT KImia Farma tbk. wordpress. Dipetik dari David parsaoran blog : http:// davidparsaoran.wordpress.com/2009/11/04/ skandal-manipulasi-laporan-keuangan-pt-kimiafarma-tbk/

Roychowdhury, S. 2004. Management of earnings through the manipulation of real activities that affect cash flow from operations. Doctoral dissertation, university of Rochester. William E. Simon Graduate School of Business Administration.

Stubben, S. 2010. Discretionary Revenues as a Measure ofEarnings Management. The Accounting Review, 85(2): 695-717.

Sudiyatno, B., \& Puspitasari, E. 2010. Tobin's q dan Altman Z-Score sebagai Indikator Pengukuran Kinerja Perusahaan. Jurnal ilmiah Kajian Akuntansi, 2(1).

Sumantyo, R. 2003. Dipetik 11 7, 2013, dari Suara Merdeka: http://www.suaramerdeka.com/ harian/0302/24/eko1.htm

Tobin, J. 1969. A General Equilibrium Approach to Monetary Theory. Journal of Money, Credit and Banking, 1: 15-29.

Ujiyantho, M. A., \& Pramuka, B. A. 2007. Mekanisme Corporate Governance, Manajemen laba dan Kinerja Keuangan. Simposium Nasional Akuntansi X: 1-17. 